\title{
Moses und die Flugsaurier
}

\section{Erhard Taverna}

Dr. med., Mitglied der Redaktion

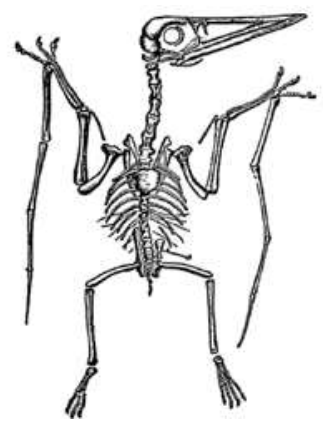

Wurden erst nach dem Sündenfall zu Fleischfressern ...
Für ein Fossil braucht es eine steinerne Kopie im geeigneten Sediment, das Fehlen von Sauerstoff und das Überstehen geologischer Faltungen. Zudem muss sie jemand finden, der versteht, was er da vor sich hat. Die meisten Lebewesen, die es jemals gab, haben keine Spuren hinterlassen. Die heutigen Funde sind Stichproben, die zudem einseitig von Meerestieren abstammen. Doch die Belege sind da, lückenhaft, oft kontrovers diskutiert, immer wieder für neue Überraschungen gut, ein Puzzle, das seit Generationen Wissenschaftler vieler Länder beschäftigt. Die Entdeckung der Tiefenzeit und Darwins Beobachtungen führten zur Vorstellung einer Evolution, die als bisher plausibelstes Konzept alle Funde in einen überprüfbaren $\mathrm{Zu}$ sammenhang stellt. Seit rund zweihundert Jahren ein vielstimmiger, offener Prozess, mit Glanzleistungen, Irrtümern, Fälschungen, Missbräuchen und umstürzenden Erkenntnissen. Raum und Zeit haben sich schwindelerregend ausgedehnt. Der Mensch betritt erst nach unvorstellbar langen Zeiträumen die Bühne des Lebens. Auf die Fragen nach dem Warum und Wohin geben die zahlreichen Forschungsgebiete keine Antwort. Doch viele Menschen möchten unumstössliche Gewissheiten, sie wünschen sich eine Heilsgeschichte mit einem vorgegeben Lebenszweck. Wer über den absoluten Durchblick, die ultimative Wahrheit zu verfügen glaubt, seine dogmatischen Lehren aus heiligen Büchern bezieht oder sonstige unfehlbare Deutungen kennt, will sich mit Nichtwissen und vorläufigen Resultaten nicht abfinden. Darum sind Kreationisten in einer desinformierten und unsicheren Gegenwart im Aufwind. Auch ausserhalb des Stammlandes USA bemühen sie sich in allen verfügbaren Medien, mit wörtlich interpretierten Bibelstellen, die bisher mehrheitsfähigen Evolutionslehren in Europa und der Schweiz zu diskreditieren. Ihre Argumente verstecken sich hinter neuen Bezeichnungen wie «Intelligent Design» oder «Nichtreduzierbare Komplexität». Ihre Ansichten sollen gleichwertig in schulischen Lehrmitteln aufgenommen werden, so geschehen vor einigen Jahren mit dem Oberstufen-Lehrmittel "NaturWert» im Kanton Bern. Es geht um viel Geld, Macht und Einflussnahme auf politische Entscheide. Dabei stehen Bildung, Medizin und Justiz im Fokus. Gut dotierte Forschungsprojekte wollen nachweisen, dass der Pterosaurus friedlich und vegetarisch mit Adam und Eva zusammenlebte, bevor er nach dem Sündenfall, zum Fleischfresser geworden,
Moses bei seinem Exodus belästigte. Das könnte man leicht als schrullige Eigenarten einer Subkultur in einer pluralistischen Gesellschaft abtun, in der auch Ufologen und Hohlweltanhänger ihren Platz haben. Liest man die Publikationen genauer, sind diese GenesisPhantasien nur eine Art Trojanisches Pferd. Immer wird der Eindruck geschürt, dass Christen eine verfolgte Minderheit, Bibelleser geächtet und Atheisten auf dem Vormarsch sind. Staatliche Sexualkunde ist abzuschaffen, Abtreibungskliniken sind abzufackeln, am besten gleich mit den Ärzten. Die Gender-Ideologie ist ein «Frontalangriff auf Gottes Ordnung im Allgemeinen und auf Christen und ihre Überzeugung im Speziellen", Blasphemie soll ein Offizialdelikt werden, Homosexelle gehören zwangstherapiert oder besser noch umgebracht. Die beste Regierungsform für die USA wäre eine christliche Theokratie mit strikter Anwendung alttestamentarischer Bestrafungsregeln, analog zur islamischen Scharia. Amerikanische Fundis mit repressiven Ansichten werden oft als "American Taliban» bezeichnet. Wer die prominentesten Wortführer anhört, findet sich in guter Gesellschaft mit rechten Republikanern und Tea-Party-Anhängern.

Noch einmal zurück zu Darwins «Origin of Species». Eine Methode, Laien zu verunsichern, besteht darin, aktuelle Kontroversen und Widersprüche der Wissenschaftsdiskussion selektiv aufzugreifen und als Beweise für die eigene Sache umzubiegen. Ein gutes Beispiel ist die vielzitierte Laborentdeckung von Mary Schweitzer, einer amerikanischen Paläontologin, die im Knochen von Sauriern wiederholt Proteinsequenzen von Elastin und Kollagen nachwies. Gemäss geltender Lehrmeinung können Proteine höchstens eine Million Jahre überdauern. Die wissenschaftliche Diskussion dauert immer noch an, dabei geht es um Nachweismethoden und den Ausschluss von Verunreinigungen, doch nie um das effektive Alter der Fossilfunde. Was im Femurknochen eines Hadrosaurus vorliegt, könnte dazu verhelfen, eine überholte Annahme zu korrigieren und den Stammbaum der Saurier neu zu ordnen. Nicht mehr und nicht weniger.

Doch für Kreationisten ist die Sache ganz klar: Saurier müssen viel jünger sein als bisher angenommen. Umso schlimmer für die Kirchgängerin Mary Schweitzer, wenn sie den Methoden der Forschung verpflichtet bleibt. Kreationisten brauchen diesen Aufwand nicht. Sie meinen die Antwort zu kennen, denn schliesslich steht es geschrieben. 